\title{
Intravenous magnesium prevents atrial fibrillation after coronary artery bypass grafting: a meta- analysis of 7 double-blind, placebo-controlled, randomized clinical trials
}

Wan-Jie Gu', Zhen-Jie Wu², Peng-Fei Wang ${ }^{3}$, Lynn Htet Htet Aung ${ }^{1}$ and Rui-Xing Yin ${ }^{1 *}$

\begin{abstract}
Background: Postoperative atrial fibrillation (POAF) is the most common complication after coronary artery bypass grafting (CABG). The preventive effect of magnesium on POAF is not well known. This meta-analysis was undertaken to assess the efficacy of intravenous magnesium on the prevention of POAF after CABG.

Methods: Eligible studies were identified from electronic databases (Medline, Embase, and the Cochrane Library). The primary outcome measure was the incidence of POAF. The meta-analysis was performed with the fixed-effect model or random-effect model according to heterogeneity.

Results: Seven double-blind, placebo-controlled, randomized clinical trials met the inclusion criteria including 1,028 participants. The pooled results showed that intravenous magnesium reduced the incidence of POAF by 36\% (RR 0.64 ; $95 \%$ confidence interval $(C \mathrm{Cl}) 0.50-0.83 ; P=0.001$; with no heterogeneity between trials (heterogeneity $P=0.8$, $\left.P^{2}=0 \%\right)$.

Conclusions: This meta-analysis indicates that intravenous magnesium significantly reduces the incidence of POAF after CABG. This finding encourages the use of intravenous magnesium as an alternative to prevent POAF after $C A B G$. But more high quality randomized clinical trials are still need to confirm the safety.
\end{abstract}

\section{Introduction}

Postoperative atrial fibrillation (POAF) is the most common complication encountered following coronary artery bypass grafting (CABG). It generally occurs between 24 and $96 \mathrm{~h}$ postoperatively, with a peak incidence on the second postoperative day [1-3]. With continuous electrocardiographic monitoring, the incidence of atrial fibrillation after CABG reported in previous studies varies from $10 \%$ to $50 \%[1,2,4]$, and this incidence has not decreased despite improvements in anesthetic and surgical techniques $[5,6]$. Furthermore, atrial fibrillation potentially leads to complications, including stroke [7-9], extended duration of hospitalization [7-10], and increasing costs $[1,9,10]$.

\footnotetext{
* Correspondence: yinruixing@yahoo.com.cn

'Department of Cardiology, Institute of Cardiovascular Diseases, the First Affiliated Hospital, Guangxi Medical University, 22 Shuangyong Road,

Nanning 530021, Guangxi, People's Republic of China

Full list of author information is available at the end of the article
}

The etiology of atrial fibrillation after CABG is unclear. The cause may be multifactorial, such as advanced age, previous history of atrial fibrillation, and low blood magnesium concentrations [11-13]. There are many pharmacologic agents to prevent POAF, but none of them are effective for all patients and are free of complications [14]. Particularly, magnesium seems to be with great promise to prevent POAF following CABG.

A previous meta-analysis of magnesium for prevention of atrial fibrillation after CABG including eight randomized controlled trials was published in 2005 [15]. The analysis showed that intravenous magnesium is associated with a significant reduction in the incidence of atrial fibrillation after CABG, with a relative risk of 0.64 (95\% confidence interval (CI) 0.47-0.87). But this meta-analysis included some clinical studies which had a modest sample size. Moreover, some of these included studies are of low quality. Recently, an increasing number of studies on the 
efficacy of intravenous magnesium on the prevention of POAF have been published. These studies have contrasted in these randomized controlled trials. Therefore, we performed an updated meta-analysis only based on doubleblind, placebo-controlled, randomized clinical trials to re-examine the effects of intravenous magnesium on the prevention of POAF after CABG.

\section{Materials and methods}

\section{Search strategy and selection criteria}

Two investigators (WJG and ZJW) independently searched the literatures collected in Medline, Embase, and the Cochrane Library up to August 1, 2011. Search terms included: magnesium, fibrillation. The searches were limited to English publications in humans. We screened the reference lists of included studies and related publications. The results were then hand searched for eligible trials. We did not include abstracts or meeting proceedings. This search strategy was performed iteratively until no new potential citations could be found on review of the reference lists of retrieved articles.

We included full-text publications when the following inclusion criteria were met: adult patients undergoing CABG only; randomized allocation to magnesium group or control group (only placebo); double-blind, placebocontrolled, randomized clinical trial; and providing available data on the incidence of POAF. Exclusion criteria included: (a) unavailable duration of follow-up; and (b) some patients reported with pre-existing atrial fibrillation. The trials with small sample size of $(n<10)$ were also excluded to avoid selection bias.

\section{Data extraction and quality assessment}

Two investigators (WJG and ZJW) independently extracted the following information from each study: the first author's name, year of publication, country of origin, participants' characteristics, study design (randomized), type of controls (placebo), data collection (prospective or not), sampling method (consecutive or not), type of blinding (double blind), duration of follow-up, regimen of magnesium administration, the timing of magnesium infusion was initiated (preoperative, intraoperative, or postoperative), number, mean age and percentage of males in each trial, total number of individuals, and the incidence of POAF in each group. When the same population was reported in several publications, we retained only the most informative article or completed study to avoid duplication of information. Any disagreements were resolved through discussion and consensus.

The methodological quality of the studies included in the meta-analysis was scored using validated Jadad 5point scale. The scale consists of three items describing randomization ( $0-2$ points), double-blind ( $0-2$ points), and drop-outs and withdrawals ( $0-1$ points) in the report of a randomized controlled trial. One point was given when one quality criterion was met. The quality scale ranges from 0 to 5 points. Higher scores indicate better reporting. The studies are said to be of low quality if the Jadad score is $\leq 2$ and high quality if the score is $\geq 3$ $[16,17]$.

\section{Statistical analysis}

Data were analyzed using Stata version 11 (Stata Corporation, College Station, TX, USA). A statistical test with a $P$ value less than 0.05 was considered significant. The incidence of POAF was treated as dichotomous variables and was expressed as risk ratio (RR) with 95\% CI for each study. Pooled estimates of efficacy were calculated using the Man-tel-Haenszel fixed-effects model [18]. But if there was heterogeneity, the following methods were used to deal with it: (a) subgroup analysis; (b) sensitivity analysis performed by excluding trials which potentially biased the results. If heterogeneity still potentially existed, the DerSimonian and Lair random-effects model was used. A test for heterogeneity, defined as variation among the results of individual trials for a given treatment beyond that expected from chance, was used to assess whether the magnitude of a given preventive effect varied between the trials. We assessed heterogeneity with $I^{2}$, which describes the percentage of total variation across studies due to heterogeneity rather than chance. $I^{2}$ can be calculated as: $I^{2}=$ $100 \% \times(\mathrm{Q}-\mathrm{df}) / \mathrm{Q}(\mathrm{Q}=$ Cochrane's heterogeneity statistics, $\mathrm{df}=$ degrees of freedom). Negative values of $I^{2}$ equaled zero, so that $I^{2}$ ranged between $0 \%$ (that is no observed heterogeneity) and 100\%. High values would show increasing heterogeneity. Studies with an $I^{2}$ statistic of $25 \%$ to $50 \%$ are considered to have low heterogeneity, those with an $I^{2}$ statistic of $50 \%$ to $75 \%$ are considered to have moderate heterogeneity, and those with an $I^{2}$ statistic of $>75 \%$ are considered to have a high degree of heterogeneity [19]. The presence of publication bias was evaluated by using the Egger test [20].

\section{Results}

Seven double-blind, placebo-controlled, randomized clinical trials consisting of 1,028 individuals were included in this study. Four of the eight randomized controlled trials published by Alghamdi et al. [15] were also included and the remaining four trials were excluded because they were non-double-blind. Three eligible studies were published after 2003. The flow of identified studies through the selection process is shown in Figure 1.

\section{Description of eligible trials}

The efficacy of intravenous magnesium with placebo on the prevention of POAF was compared in these trials. The baseline characteristics of included studies are shown in Table 1 and the design characteristics are 


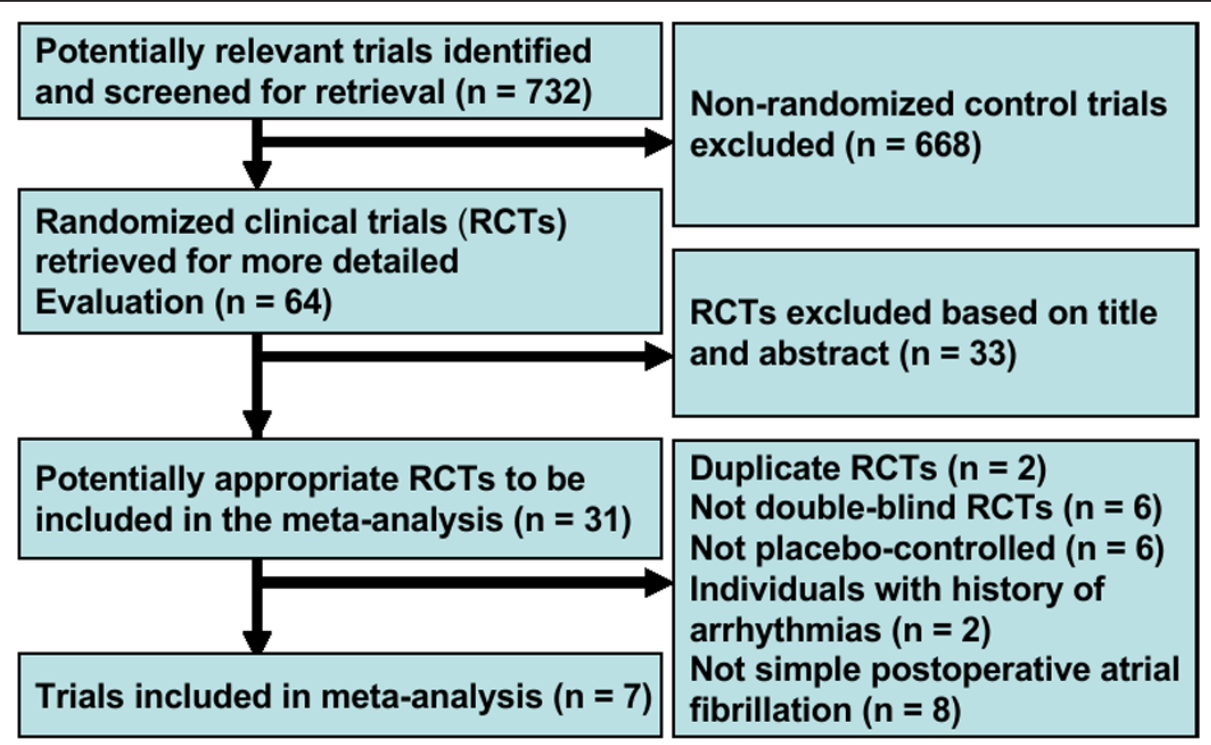

Figure 1 Process of study selection of double-blind, placebo-controlled, randomized trials.

presented in Table 2. Of the seven trials, two were done in the USA, one in UK, one in Turkey, one in Switzerland, one in Iran, and one in Pakistan. The number of participants ranged from 50 to 345 . All trials included both men and women. The total dosage of intravenous magnesium in the intervention groups ranged from 8 to $100 \mathrm{mmol}$ (one trial [21] was not available). The followup time ranged from 1 to 5 days (one trial [11] was followed up until atrial fibrillation developed and needed therapeutic intervention). All trials reported perioperative prophylactic use of intravenous magnesium: one trial [21] was initiated during the preoperative period, two trials $[11,22]$ during the intraoperative period, and four trials [23-26] during the postoperative period.

\section{Quality assessment of the trials}

The trials included in this meta-analysis appeared to have been reasonably designed and conducted. All studies had a statement regarding randomization and double-blind. Four trials described the methods of randomization. Four trials reported the withdrawals or dropouts. All trials described the main outcome, and no missing data seemed to influence the results. The quality of the included studies was assessed by the Jadad score. The median Jadad score of the studies included was 4 (range from 3 to 5 , Table 2).

\section{The incidence of POAF}

Analysis of pooled prevalence of preoperative patient group characteristics revealed that no differences were observed for history of coexistence of basic diseases (for example diabetes mellitus, hypertension) and routine prophylactic therapies (for example $\beta$-blockers; Table 3 ).
Pooling all seven trials, of 511 patients in the pooled intervention (intravenous magnesium) group, 76 developed POAF, compared to 116 out of 517 patients in the pooled control group. The pooled analysis showed that intravenous magnesium significantly reduced the incidence of POAF by $36 \%$ (RR $0.64 ; 95 \%$ CI $0.50-0.83 ; P=$ 0.001 ; Figure 2), with no heterogeneity between trials (heterogeneity $P=0.8 ; I^{2}=0 \%$ ).

Subgroup analyses were done according to data collection, sampling method and the duration of follow-up. Pooled results of five prospective trials $[11,21,23,24,26]$ showed intravenous magnesium significantly reduced the incidence of POAF by $37 \%$ (RR 0.63, 95\% CI 0.48-0.83; $P=0.001$; heterogeneity $\left.P=0.7, I^{2}=0 \%\right)$. Pooled results of four consecutive patients trials $[11,23,24,26]$ showed that intravenous magnesium significantly reduced the incidence of POAF by $44 \%$ (RR $0.56,95 \%$ CI $0.37-0.83 ; P=$ 0.005 ; heterogeneity $\left.P=0.7, I^{2}=0 \%\right)$. Exclusion of the Hamid et al. trial [22] in which the duration of follow-up is just 1 day yielded similar results (RR 0.66 , 95\% CI 0.51 $0.85 ; P=0.002$; heterogeneity $\left.P=0.8 ; I^{2}=0 \%\right)$. The summary of subgroup analyses results is shown in Table 4 .

\section{Publication bias}

Assessment of publication bias using Egger's test showed that moderate publication bias existed among the included trials (Egger's test: $P=0.045$; Figure 3 ).

\section{Discussion}

This is a further meta-analysis to evaluate the relationship between intravenous magnesium and POAF. All trials included in this analysis are double-blind, placebocontrolled, randomized clinical trials. The data can give 


\section{Table 1 Characteristics of studies included in the meta-analysis}

\begin{tabular}{|c|c|c|c|c|c|c|c|c|c|c|}
\hline \multirow[t]{2}{*}{ Author } & \multirow[t]{2}{*}{$n$} & \multirow[t]{2}{*}{ Regimen of magnesium administration ${ }^{a}$} & \multirow{2}{*}{$\begin{array}{l}\text { Control } \\
\text { regimen } \\
\text { (route) }\end{array}$} & \multirow{2}{*}{$\begin{array}{l}\text { Total dose } \\
\mathrm{Mg}^{2+}(\mathrm{mmol})\end{array}$} & \multicolumn{2}{|l|}{ Magnesium } & \multicolumn{2}{|l|}{ Controls } & \multicolumn{2}{|l|}{ POAF } \\
\hline & & & & & $\begin{array}{l}\text { Age (years), } \\
\text { (male, \%) }\end{array}$ & $n$ & $\begin{array}{l}\text { Age (years), } \\
\text { (male, \%) }\end{array}$ & $n$ & $\begin{array}{l}\text { Magnes } \\
(\%) \text { Con } \\
(\%)\end{array}$ & sium \\
\hline $\begin{array}{l}\text { Fanning et } \\
\text { al.[23] }\end{array}$ & 99 & $168 \mathrm{mEq}$ over the first 4 postoperative days & $\begin{array}{l}5 \% \text { dextrose } \\
\text { solution (IV) }\end{array}$ & $84 \mathrm{mmol}$ & $59(43-75)$ & $\begin{array}{l}49 \\
(71.4)\end{array}$ & $62(42-79)$ & $\begin{array}{l}50 \\
(78)\end{array}$ & $\begin{array}{l}7 / 49 \\
(14.3)\end{array}$ & $\begin{array}{l}14 / 50 \\
(28)\end{array}$ \\
\hline $\begin{array}{l}\text { Colquhoun } \\
\text { et al.[24] }\end{array}$ & 130 & $50 \mathrm{mmol}$ during the first $48 \mathrm{~h}$ after surgery & $\begin{array}{l}5 \% \text { dextrose } \\
\text { solution (IV) }\end{array}$ & $50 \mathrm{mmol}$ & $57.1 \pm 8.4$ & $\begin{array}{l}66 \\
(83.3)\end{array}$ & $58.7 \pm 7.9$ & $\begin{array}{l}64 \\
(79.7)\end{array}$ & $\begin{array}{l}11 / 66 \\
(16.7)\end{array}$ & $\begin{array}{l}15 / 64 \\
(23.4)\end{array}$ \\
\hline $\begin{array}{l}\text { Nurozler et } \\
\text { al.[26] }\end{array}$ & 50 & $\begin{array}{l}100 \mathrm{mEq} \text { on the first operative day and } 25 \mathrm{mEq} \text { per day from second to fifth } \\
\text { days }\end{array}$ & Placebo (IV) & $100 \mathrm{mmol}$ & $56.3 \pm 1.6$ & $\begin{array}{l}25 \\
(92)\end{array}$ & $53.6 \pm 2.0$ & $\begin{array}{l}25 \\
(92)\end{array}$ & $\begin{array}{l}1 / 25 \\
(4)\end{array}$ & $\begin{array}{l}5 / 25 \\
(20)\end{array}$ \\
\hline $\begin{array}{l}\text { Treggiari- } \\
\text { Venzi et al. } \\
{[25]}\end{array}$ & 98 & $4 \mathrm{~g}$ per $24 \mathrm{~h}$ continuous infusion for $72 \mathrm{~h}$ starting within $1 \mathrm{~h}$ of arrival in the ICU & $\begin{array}{l}0.9 \% \mathrm{NaCl} \\
\text { solution (IV) }\end{array}$ & $48 \mathrm{mmol}$ & $65(46-81)$ & $\begin{array}{l}47 \\
(89.4)\end{array}$ & $65(37-88)$ & $\begin{array}{l}51 \\
(84.3)\end{array}$ & $\begin{array}{l}11 / 47 \\
(23)\end{array}$ & $\begin{array}{l}14 / 51 \\
(27)\end{array}$ \\
\hline $\begin{array}{l}\text { Hazelrigg et } \\
\text { al.[21] }\end{array}$ & 202 & $\begin{array}{l}80 \mathrm{mg} / \mathrm{kg} \text { (ideal body weight) before cardiopulmonary bypass (CPB), } 8 \mathrm{mg} / \mathrm{kg} / \mathrm{h} \\
\text { (ideal body weight) intravenous (IV) infusion continued for } 48 \mathrm{~h}\end{array}$ & $\begin{array}{l}5 \% \text { dextrose } \\
\text { solution (IV) }\end{array}$ & NA & $62.1 \pm 9.5$ & $\begin{array}{l}105 \\
(74)\end{array}$ & $63.7 \pm 11.1$ & $\begin{array}{l}97 \\
(68)\end{array}$ & $\begin{array}{l}32 / 105 \\
(30.5)\end{array}$ & $\begin{array}{l}41 / 97 \\
(42.3)\end{array}$ \\
\hline $\begin{array}{l}\text { Najafi et al. } \\
\text { [11] }\end{array}$ & 345 & $\begin{array}{l}2 \mathrm{~g} \text { after induction of anesthesia until the start of cardiopulmonary bypass (CPB) } \\
\text { and } 8 \mathrm{~g} \text { after CABG until } 24 \mathrm{~h} \text { after surgery }\end{array}$ & Placebo (IV) & $40 \mathrm{mmol}$ & $59.1(9.1)$ & $\begin{array}{l}166 \\
(75.9)\end{array}$ & $59.7(9.9)$ & $\begin{array}{l}179 \\
(76.5)\end{array}$ & $\begin{array}{l}12 / 166 \\
(7.2)\end{array}$ & $\begin{array}{l}22 / 179 \\
(12.3)\end{array}$ \\
\hline $\begin{array}{l}\text { Hamid et al. } \\
\text { [22] }\end{array}$ & 104 & $2 \mathrm{~g}$ after intubation & $\begin{array}{l}0.9 \% \mathrm{NaCl} \\
\text { solution (IV) }\end{array}$ & $8 \mathrm{mmol}$ & $58.3 \pm 7.6$ & $\begin{array}{l}53 \\
(98)\end{array}$ & $56.3 \pm 8.9$ & $\begin{array}{l}51 \\
(86)\end{array}$ & $\begin{array}{l}2 / 53 \\
(3.77)\end{array}$ & $\begin{array}{l}5 / 51 \\
(9.8)\end{array}$ \\
\hline
\end{tabular}

a To convert units of $\mathrm{g}$ and $\mathrm{mEq}$ to $\mathrm{mmol}$, the following conversions were used; $1 \mathrm{~g}=4 \mathrm{mmol}=8 \mathrm{mEq}$ for $\mathrm{MgSO} 4$.

CABG, coronary artery bypass grafting; CPB, cardiopulmonary bypass; ICU, intensive care unit;lV, intravenous; $n$, number of participants; NA, data not available; POAF, postoperative atrial fibrillation; 
Table 2 Included studies design characteristics

\begin{tabular}{|c|c|c|c|c|c|c|c|c|}
\hline Author & $\begin{array}{l}\text { Publication } \\
\text { year }\end{array}$ & Country & Study design & $\begin{array}{l}\text { Data } \\
\text { collection }\end{array}$ & $\begin{array}{l}\text { Sampling } \\
\text { method }\end{array}$ & Blind & $\begin{array}{l}\text { Follow-up } \\
\text { (days) }\end{array}$ & $\begin{array}{l}\text { Jadad } \\
\text { score }\end{array}$ \\
\hline Fanning et al.[23] & 1991 & USA & Randomized, placebo-controlled & Prospective & Consecutive & $\mathrm{DB}$ & 4 & 4 \\
\hline Colquhoun et al.[24] & 1993 & UK & Randomized, placebo-controlled & Prospective & Consecutive & DB & 4 & 4 \\
\hline Nurozler et al.[26] & 1996 & Turkey & Randomized, placebo-controlled & Prospective & Consecutive & DB & 5 & 3 \\
\hline Treggiari-Venzi et al.[25] & 2000 & Switzerland & Randomized, placebo-controlled & NA & NA & DB & 3 & 5 \\
\hline Hazelrigg et al.[21] & 2004 & USA & Randomized, placebo-controlled & Prospective & NA & DB & 5 & 4 \\
\hline Najafi et al.[11] & 2007 & Iran & Randomized, placebo-controlled & Prospective & Consecutive & DB & $\begin{array}{l}\text { Until AF } \\
\text { developed and } \\
\text { needed } \\
\text { therapeutic } \\
\text { intervention }\end{array}$ & 4 \\
\hline Hamid et al.[22] & 2008 & Pakistan & Randomized, placebo-controlled & NA & NA & DB & 1 & 4 \\
\hline
\end{tabular}

$\mathrm{AF}$, atrial fibrillation; $\mathrm{DB}$, double-blind; NA, data not available

greater power to assess the efficacy of intravenous magnesium on the prevention of atrial fibrillation after CABG. We combined the effect sizes of all seven included trials that used intravenous magnesium for preventing POAF through a fixed-effects model and found that intravenous magnesium significantly reduced the incidence of POAF by $36 \%$. A meta-analysis of data collected before December 2003 [15] found a cumulative RR of 0.64 (95\% CI: 0.47-0.87) for the randomized controlled trials. Our findings are consistent with this previous meta-analysis.

This meta-analysis shows diversity in the dosing, timing and duration of magnesium administration. The diversity accounts for the inconsistency in the reported outcomes of the included trials as listed in Table 1. In three $[23,24,26]$ of the prospectively controlled clinical trials $[11,21,23,24,26]$, intravenous magnesium significantly reduced the incidence of POAF after CABG. In three trials, magnesium was dosed for at least 2 consecutive days postoperatively. Given that the onset of POAF following CABG generally occurs between 24 and 96 h postoperatively, with a peak incidence on the second postoperative day and that it is often associated with hypomagnesaemia, intravenous magnesium supplementation during this period may play a key role in the suppression of POAF.

Demographic bias owing to generating the sequence of randomization inadequately may be another reason for the discordance in the reported results of magnesium prophylaxis. The biased variable, if it happens to be a powerful predictor of POAF, would apparently have a strong influence on the outcome of the study. For example, one trial [22] showed that prophylactic magnesium supplementation does not significantly reduce the incidence of POAF, patients in the magnesium group had a higher ratio of male gender (98\% versus $86 \%, P=0.02$ ). This characteristic, male gender has been consistently a risk factor for the development of POAF.

Up to now, various preventive methods including pharmacologic and non-pharmacologic interventions have been proposed in the preventive strategy of POAF. Current evidences from meta-analyses [27-29] suggest that beta-blockers are effective and safe for most patients and advise that clinicians should not discontinue betablockers before cardiac surgery, unless contraindicated. Amiodarone can be safely added in patients at high risk for atrial fibrillation. In a recent meta-analysis, however, Patel et al. [30] found that amiodarone increases the risk of bradycardia and hypotension, particularly when administered intravenously. Meta-analyses of the clinical trials $[8,29,31]$ investigating the effect of prophylactic pacing have consistently suggested that single- or dual-site atrial pacing significantly reduces the incidence of POAF; however, it is limited in practical use because of its complexity. Furthermore, there are some other pharmaceuticals such as statins [32,33], N-3 polyunsaturated fatty acids [34], and anti-inflammatory agents $[35,36]$ being used to prevent POAF following CABG. However, the number of enrolled patients in these trails was small, and the pharmaceutical doses and administration times varied widely among studies. Thus, further studies are still necessary before confirmed conclusion. In a prospective, randomized, double-blind, placebo-controlled study, Cagli et al. [37] have concluded that low-dose amiodarone and

Table 3 Perioperative variables of the patients

\begin{tabular}{|c|c|c|c|c|c|}
\hline Variable & Magnesium (\% (n)) & Control (\% (n)) & $x^{2}$ value & $P$ value & Total prevalence $(\%(n))$ \\
\hline Diabetes mellitus [11,24-26] & $22.4(68 / 304)$ & $21.9(70 / 319)$ & 0.016 & 0.9 & $22.2(138 / 623)$ \\
\hline Hypertension [24-26] & $31.2(43 / 138)$ & $27.1(38 / 140)$ & 0.543 & 0.5 & $29.1(81 / 278)$ \\
\hline $\boldsymbol{\beta}$-blocker [21-25] & $45.6(146 / 320)$ & $48.6(152 / 313)$ & 0.548 & 0.5 & $47.1(298 / 633)$ \\
\hline
\end{tabular}




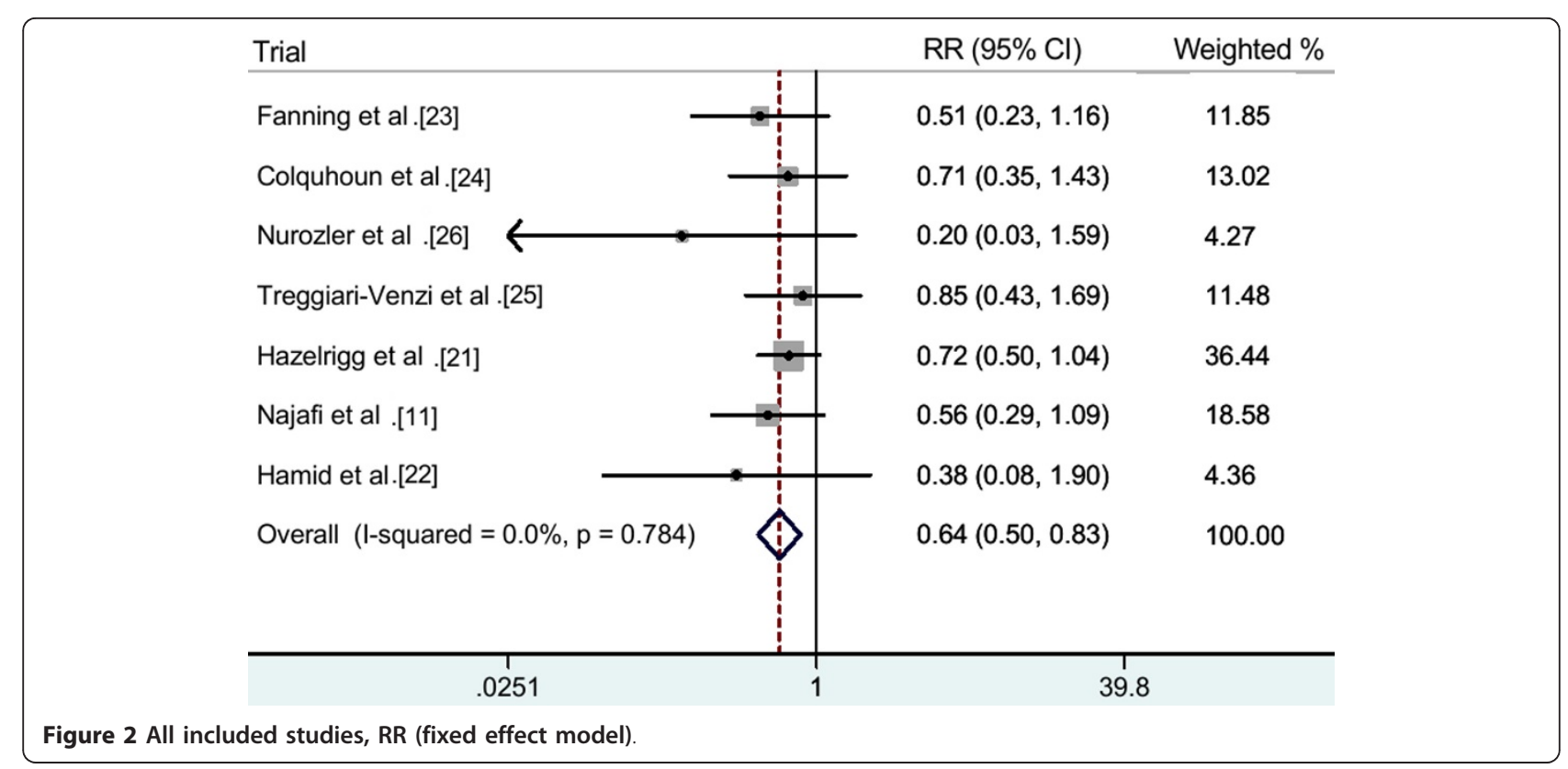

Table 4 The summary of subgroup analyses results

\begin{tabular}{lcccccc}
\hline Subgroup analysis & Studies $(\boldsymbol{n})$ & Participants $(\boldsymbol{n})$ & RR $(\mathbf{9 5} \% \mathbf{C l})$ & $\boldsymbol{I}^{\mathbf{2}}(\%)$ & $\boldsymbol{P}$ heterogeneity & $\boldsymbol{P}$ value \\
\hline Prospective & 5 & 826 & $0.63(0.48-0.83)$ & 0.00 & 0.7 & 0.001 \\
Consecutive & 4 & 624 & $0.56(0.37-0.83)$ & 0.00 & 0.7 & 0.005 \\
Follow-up & 6 & 924 & $0.66(0.51-0.85)$ & 0.00 & 0.8 & 0.002 \\
\hline
\end{tabular}

$\mathrm{Cl}$, confidence interval; $n$, number of studies; $\mathrm{RR}$, risk ratio

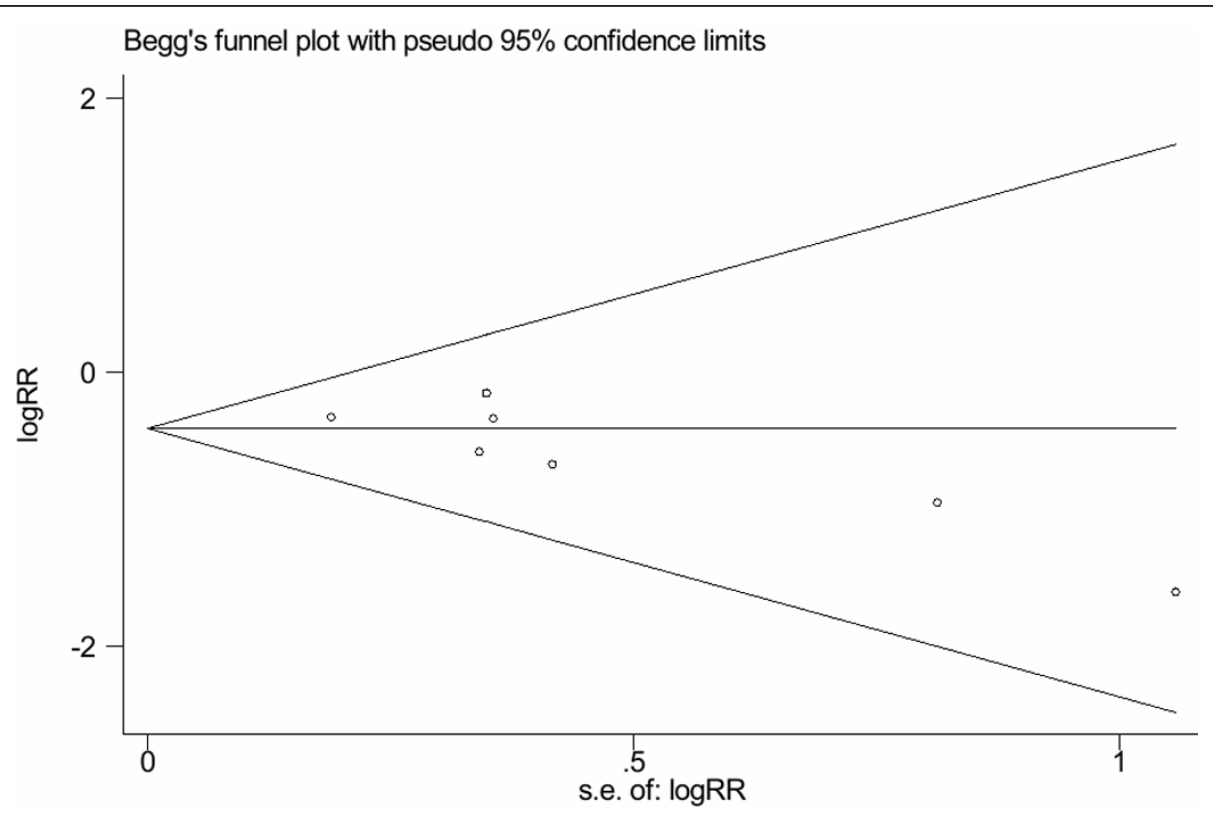

Figure 3 Tests for publication bias for RR of the incidence of POAF 
magnesium combination is an effective, simple, well-tolerated, and possibly cost-effective regimen to prevent atrial fibrillation after CABG for high-risk patients. Perhaps appropriate combinations of these pharmacologic and non-pharmacologic interventions might be of benefit for further reducing POAF. In this meta-analysis, the patient population enrolled was quite homogeneous in its presentation. The studies included are of high quality, and all seven studies are double-blind, placebocontrolled, randomized trials having a Jadad score of $\geq 3$. We combined all the studies using a fixed-effects mode and tested heterogeneity between trials with $I^{2}(0.0 \%)$ and with $P$ value (0.8), indicating no heterogeneity.

Several potential limitations of this meta-analysis merit consideration. First, we accept that our meta-analysis included some clinical studies which had a modest sample size. Although we aimed to retrieve additional data from investigators, it was inevitable that some missing and unpublished data may still exist. Second, the exclusion of non-English-language studies and studies with fewer than 10 patients may lead to bias in effect size. In addition, follow-up time varied among included studies, and different total dose of intravenous magnesium was adopted in these studies. The discrepancy may explain clinical heterogeneity among studies, although no statistical heterogeneity is found.

\section{Conclusion}

This meta-analysis of all seven double-blind, placebo-controlled, randomized clinical trials shows that intravenous magnesium significantly reduced the incidence of POAF after CABG by $36 \%$. Pooled analysis of five prospective trials shows intravenous magnesium significantly reduced the incidence of POAF by $37 \%$, and pooled analysis of four consecutive patient trials shows that intravenous magnesium significantly reduced the incidence of POAF by $44 \%$. This finding encourages the use of intravenous magnesium as an alternative to prevent POAF after CABG but more high quality randomized clinical trials are still need to confirm the safety.

\footnotetext{
Acknowledgements

This study was supported by the Science Foundation of Guangxi Returned Oversea Scholars (No: 0991004).

\section{Author details}

${ }^{1}$ Department of Cardiology, Institute of Cardiovascular Diseases, the First Affiliated Hospital, Guangxi Medical University, 22 Shuangyong Road, Nanning 530021, Guangxi, People's Republic of China. 'Department of Colorectal and Anal Surgery, The First Affiliated Hospital, Guangxi Medical University, Nanning, Guangxi, People's Republic of China. ${ }^{3}$ Department of Orthopaedics, China-Japan Union Hospital, Jilin University, Changchun, Jilin, People's Republic of China.
}

\section{Authors' contributions}

WJG conceived the study, participated in the design, collected the data, and drafted the manuscript. ZJW collected the data, and performed statistical analyses. PFW and LHHA helped to collect the data. RXY conceived the study, participated in the design, and helped to draft the manuscript. All authors read and approved the final manuscript.

\section{Competing interests}

The authors declare that they have no competing interests.

Received: 28 September 2011 Accepted: 20 April 2012

Published: 20 April 2012

\section{References}

1. Aranki SF, Shaw DP, Adams DH, Rizzo RJ, Couper GS, VanderVliet M, Collins JJ Jr, Cohn LH, Burstin HR: Predictors of atrial fibrillation after coronary artery surgery. Current trends and impact on hospital resources. Circulation 1996, 94:390-397.

2. Solomon AJ, Berger AK, Trivedi KK, Hannan RL, Katz NM: The combination of propranolol and magnesium does not prevent postoperative atrial fibrillation. Ann Thorac Surg 2000, 69:126-129.

3. Kaplan M, Kut MS, Icer UA, Demirtas MM: Intravenous magnesium sulfate prophylaxis for atrial fibrillation after coronary artery bypass surgery. J Thorac Cardiovasc Surg 2003, 125:344-352.

4. Forlani S, De Paulis R, de Notaris S, Nardi P, Tomai F, Proietti I, Ghini AS, Chiariello L: Combination of sotalol and magnesium prevents atrial fibrillation after coronary artery bypass grafting. Ann Thorac Surg 2002, 74:720-726.

5. Michelson EL, Morganfoth J, Mac Vough H: Postoperative arrhythmias after coronary artery and cardiac valvular surgery detected by long-term electrocardiographic monitoring. Am Heart J 1979, 97:442-448.

6. Rose MR, Glassman E, Spencer FC: Arrhythmias following cardiac surgery: relation to serum digoxin levels. Am Heart J 1975, 89:288-294.

7. Almassi GH, Schowalter T, Nicolosi AC, Aggarwal A, Moritz TE, Henderson WG, Tarazi R, Shroyer AL, Sethi GK, Grover FL, Hammermeister KE: Atrial fibrillation after cardiac surgery: a major morbid event? Ann Surg 1997, 226:501-513.

8. Crystal E, Connolly SJ, Sleik K, Ginger TJ, Yusuf S: Interventions on prevention of postoperative atrial fibrillation in patients undergoing heart surgery: a meta-analysis. Circulation 2002, 106:75-80.

9. Taylor GJ, Mikell FL, Moses HW, Dove JT, Katholi RE, Malik SA, Markwell SJ, Korsmeyer C, Schneider JA, Wellons HA: Determinants of hospital charges for coronary artery bypass surgery: the economic consequences of postoperative complications. Am J Cardiol 1990, 65:309-313.

10. Daoud EG, Strickberger SA, Man KC, Goyal R, Deeb GM, Bolling SF, Pagani FD, Bitar C, Meissner MD, Morady F: Preoperative amiodarone as prophylaxis against atrial fibrillation after heart surgery. N Engl J Med 1997, 337:1785-1791

11. Najafi M, Hamidian R, Haghighat B, Fallah N, Tafti HA, Karimi A Boroumand MA: Magnesium infusion and postoperative atrial fibrillation: a randomized clinical trial. Acta Anaesthesiol Taiwan 2007, 45:89-94.

12. Kohno H, Koyanagi T, Kasegawa H, Miyazaki M: Three-day magnesium administration prevents atrial fibrillation after coronary artery bypass grafting. Ann Thorac Surg 2005, 79:117-126.

13. Aerra V, Kuduvalli M, Moloto AN, Srinivasan AK, Grayson AD, Fabri BM, Oo AY: Does prophylactic sotalol and magnesium decrease the incidence of atrial fibrillation following coronary artery bypass surgery: a propensity-matched analysis. J Cardiothorac Surg 2006, 1:6

14. Ho KM, Lewis JP: Prevention of atrial fibrillation in cardiac surgery: time to consider a multimodality pharmacological approach. Cardiovasc Ther 2010, 8:59-65

15. Alghamdi AA, Al-Radi OO, Latter DA: Intravenous magnesium for prevention of atrial fibrillation after coronary artery bypass surgery: a systematic review and meta-analysis. J Card Surg 2005, 20:293-299.

16. Jadad AR, Moore RA, Carroll D, Jenkinson C, Reynolds DJ, Gavaghan DJ, McQuay $\mathrm{HJ}$ : Assessing the quality of reports of randomized clinical trials: is blinding necessary? Control Clin Trials 1996, 17:1-12.

17. Moher D, Pham B, Jones A, Cook DJ, Jadad AR, Moher M, Tugwell P, Klassen TP: Does quality of reports of randomised trials affect estimates of intervention efficacy reported in meta-analyses? Lancet 1998, 352:609-613.

18. Sutton AJ, Abrams KR, Jones DR: An illustrated guide to the methods of meta-analysis. J Eval Clin Pract 2001, 7:135-148. 
19. Higgins JP, Thompson SG, Deeks JJ, Altman DG: Measuring inconsistency in meta-analyses. BMJ 2003, 327:557-560.

20. Egger M, Davey Smith G, Schneider M, Minder C: Bias in meta-analysis detected by a simple, graphical test. BMJ 1997, 315:629-634.

21. Hazelrigg SR, Boley TM, Cetindag IB, Moulton KP, Trammell GL, Polancic JE, Shawgo TS, Quin JA, Verhulst S: The efficacy of supplemental magnesium in reducing atrial fibrillation after coronary artery bypass grafting. Ann Thorac Surg 2004, 77:824-830.

22. Hamid M, Kamal RS, Sami SA, Atiq F, Shafquat A, Naqvi HI, Khan FH: Effect of single dose magnesium on arrhythmias in patients undergoing coronary artery bypass surgery. J Pak Med Assoc 2008, 58:22-27.

23. Fanning WJ, Thomas CS Jr, Roach A, Tomichek R, Alford WC, Stoney WS Jr: Prophylaxis of atrial fibrillation with magnesium sulfate after coronary artery bypass grafting. Ann Thorac Surg 1991, 52:529-533.

24. Colquhoun IW, Berg GA, el-Fiky M, Hurle A, Fell GS, Wheatley DJ: Arrhythmia prophylaxis after coronary artery surgery. A randomised controlled trial of intravenous magnesium chloride. Eur J Cardiothorac Surg 1993, 7:520-523.

25. Treggiari-Venzi MM, Waeber $J \mathrm{~L}$, Perneger TV, Suter PM, Adamec $R$, Romand JA: Intravenous amiodarone or magnesium sulphate is not costbeneficial prophylaxis for atrial fibrillation after coronary artery bypass surgery. Br J Anaesth 2000, 85:690-695.

26. Nurözler F, Tokgözoglu L, Pasaoglu I, Böke E, Ersoy U, Bozer AY: Atrial fibrillation after coronary artery bypass surgery: Predictors and the role of MgSO4 replacement. J Card Surg 1996, 11:421-427.

27. Andrews TC, Reimold SC, Berlin JA, Antman EM: Prevention of supraventricular arrhythmias after coronary artery bypass surgery. A meta-analysis of randomized control trials. Circulation 1991, 84(Suppl 5): |||236-244.

28. Crystal E, Garfinkle MS, Connolly SS, Ginger TT, Sleik K, Yusuf SS: Interventions for preventing post-operative atrial fibrillation in patients undergoing heart surgery. Cochrane Database Syst Rev 2004, 4:CD003611.

29. Burgess DC, Kilborn MJ, Keech AC: Interventions for prevention of postoperative atrial fibrillation and its complications after cardiac surgery: a meta-analysis. Eur Heart J 2006, 27:2846-2857.

30. Patel AA, White CM, Gillespie EL, Kluger J, Coleman Cl: Safety of amiodarone in the prevention of post-operative atrial fibrillation: a meta-analysis. Am J Health Syst Pharm 2006, 63:829-837.

31. Daoud EG, Snow R, Hummel JD, Kalbfleisch SJ, Weiss R, Augostini R. Temporary atrial epicardial pacing as prophylaxis against atrial fibrillation after heart surgery: a meta-analysis. J Cardiovasc Electrophysiol 2003, 14:127-132.

32. Marín F, Pascual DA, Roldán V, Arribas JM, Ahumada M, Tornel PL, Oliver C, Gómez-Plana J, Lip GY, Valdés M: Statins and post-operative risk of atrial fibrillation following coronary artery bypass grafting. Am J Cardiol 2006, 97:55-60.

33. Patti G, Chello M, Candura D, Pasceri V, D'Ambrosio A, Covino E, Di Sciascio G: Randomized trial of atorvastatin for reduction of postoperative atrial fibrillation in patients undergoing cardiac surgery: results of the ARMYDA-3 (Atorvastatin for Reduction of Myocardial Dysrhythmia After Cardiac Surgery) study. Circulation 2006, 114:1455-1461.

34. Liu T, Korantzopoulos P, Shehata M, Li G, Wang X, Kaul S: Prevention of atrial fibrillation with omega-3 fatty acids: a meta-analysis of randomised clinical trials. Heart 2011, 97:1034-1040.

35. Cheruku KK, Ghani A, Ahmad F, Pappas P, Silverman PR, Zelinger A, Silver MA: Efficacy of nonsteroidal anti-inflammatory medications for prevention of atrial fibrillation following coronary artery bypass graft surgery. Prev Cardiol 2004, 7:13-18.

36. Halonen J, Halonen $\mathrm{P}$, Järvinen $\mathrm{O}$, Taskinen $\mathrm{P}$, Auvinen $\mathrm{T}$, Tarkka M, Hippeläinen M, Juvonen T, Hartikainen J, Hakala T: Corticosteroids for the prevention of atrial fibrillation after cardiac surgery: a randomized controlled trial. JAMA 2007, 297:1562-1567.

37. Cagli K, Ozeke O, Ergun K, Budak B, Demirtas E, Birincioglu CL, Pac M: Effect of low-dose amiodarone and magnesium combination on atrial fibrillation after coronary artery surgery. J Card Surg 2006, 21:458-464.

doi:10.1186/1745-6215-13-41

Cite this article as: Gu et al:: Intravenous magnesium prevents atrial fibrillation after coronary artery bypass grafting: a meta-analysis of 7 double-blind, placebo-controlled, randomized clinical trials. Trials 2012 13:41.

\section{Submit your next manuscript to BioMed Central and take full advantage of:}

- Convenient online submission

- Thorough peer review

- No space constraints or color figure charges

- Immediate publication on acceptance

- Inclusion in PubMed, CAS, Scopus and Google Scholar

- Research which is freely available for redistribution 